\title{
Chemical and electrical characteristics of annealed Ni/Au and Ni/Ir/Au contacts on AlGaN
}

\author{
P. N. M. Ngoepe ${ }^{* 1}$, W. E. Meyer ${ }^{1}$, F. D. Auret ${ }^{1}$, E. Omotoso ${ }^{1}$, M. Diale ${ }^{1}$ \\ H. C. Swart ${ }^{2}$, M. M. Duvenhage ${ }^{2}$, E. Coetsee ${ }^{2}$ \\ ${ }^{I}$ Department of Physics, University of Pretoria, Private bag X20, Hatfield, 0028, South Africa \\ ${ }^{2}$ Department of Physics, University of the Free State, P.O. Box 339, Bloemfontein, 9300, South Africa \\ Corresponding author e-mail address: phuti.ngoepe@up.ac.za
}

\begin{abstract}
The evolution of $\mathrm{Ni} / \mathrm{Au}$ and $\mathrm{Ni} / \mathrm{Ir} / \mathrm{Au}$ metal contacts deposited on $\mathrm{AlGaN}$ was investigated at different annealing temperatures. The samples were studied with electrical and chemical composition techniques. $I-V$ characteristics of the Schottky diodes were optimum after 500 and $600{ }^{\circ} \mathrm{C}$ annealing for $\mathrm{Ni} / \mathrm{Au}$ and $\mathrm{Ni} / \mathrm{Ir} / \mathrm{Au}$ based diodes, respectively. The depth profiles of the contacts were measured by x-ray photoelectron spectroscopy and time of flight secondary ion mass spectroscopy. These chemical composition techniques were used to examine the evolution of the metal contacts in order to verify the influence the metals have on the electrical properties of the diodes. The insertion of Ir as a diffusion barrier between $\mathrm{Ni}$ and $\mathrm{Au}$ effected the electrical properties, improving the stability of the contacts at high temperatures. Gold diffuses into the AlGaN film, degrading the electrical properties of the $\mathrm{Ni} / \mathrm{Au}$ diode. At $500{ }^{\circ} \mathrm{C}$, the insertion of Ir, however, prevented the in-diffusion of Au into the AlGaN substrate.
\end{abstract}

Keywords: Annealing, Schottky photodiode, AlGaN

PACS: 73.40.Ei, 73.61.Ey, 78.66.Fd 


\section{Introduction}

Aluminium gallium nitride $(\mathrm{AlGaN})$ is a ternary semiconductor that has promising applications for optoelectronic devices. These applications include both emitting and detecting devices, such as light emitting diodes (LEDs) and solar-blind detectors respectively [1-4]. One of the properties that makes AlGaN a good candidate for such devices is the fact that it has a tunable wide band gap ranging from 3.4 to $6.2 \mathrm{eV}$ depending on the $\mathrm{Al}$ to $\mathrm{Ga}$ ratio. The metals deposited on the semiconductor play an important role in the transport mechanisms of the device. In order to produce a Schottky photodiode the metals have to be thin enough $(\sim 100 \AA)$ for radiation to reach the metal semiconductor interface [5]. Annealing is another way of improving the transparency of metals to radiation [6,7]. This annealing has to be optimised without degrading the electrical and optical characteristics of the photodiode. In annealing the device, the changes in chemical properties of the contact and/or the mixing of the metals to form alloys can enhance or degrade its operation [6]. Furthermore, some metals which form part of the metal scheme might degrade the device after annealing when they come in contact with the metal-semiconductor interface (or diffuse into the semiconductor). The insertion of different metals between $\mathrm{Ni} / \mathrm{Au}$ has been performed with the aim improving the electrical properties of Schottky diodes [8]. To achieve Schottky diodes on $\mathrm{n}-\mathrm{AlGaN}$, metals with a high work function are required $[9,10] . \mathrm{Ni}\left(\phi_{m}=5.15 \mathrm{eV}\right)$ and $\mathrm{Au}\left(\phi_{m}=5.1 \mathrm{eV}\right)$ were chosen not only because of this fact but because, amongst other properties, the former adheres well to AlGaN whilst the latter is a good conductor. Ngoepe et al [11] inserted Ir, as a diffusion barrier, between Ni/Au deposited on $\mathrm{AlGaN}$ and compared the evolution of the electrical and optical properties with annealing. It was found that the Ir seemed to have an influence on these properties and improved the temperature stability of the contacts. In this paper the structure of the metal contact after isochronal annealing at various 
temperatures is investigated using time of flight secondary ion mass spectrometry (TOFSIMS) and x-ray photo electron spectroscopy (XPS).

\section{Experimental}

The $\mathrm{Al}_{0.35} \mathrm{Ga}_{0.65} \mathrm{~N}$ samples were degreased by submerging them in boiling TCE and isopropanol for 3 minutes each. The samples were then rinsed 3 times in de-ionised water. Etching was performed on the samples by placing them in boiling aqua regia for 10 minutes and then in a $\mathrm{HCl}: \mathrm{H}_{2} \mathrm{O}$ solution for 60 seconds. Between the etching steps de-ionised water was again used to rinse the samples [12]. Lastly, the samples were blown dry with $\mathrm{N}_{2}$. $\mathrm{Ni}$ (20 $\AA) / \mathrm{Au}(50 \AA)$ and Ni $(20 \AA) / \mathrm{Ir}(30 \AA) / \mathrm{Au}(50 \AA)$ metal schemes were deposited on the surface of the $\mathrm{AlGaN}$ wafers using a resistive evaporation system and an electron beam system respectively.

Six identical samples were prepared simultaneously for each deposition method. One sample was set aside for measurement of the as-grown characteristics. The remaining samples were then annealed for 5 minutes at $200{ }^{\circ} \mathrm{C}$, and one of these samples set aside for measurement. This process was repeated for annealing at $300,400,500$, and $600{ }^{\circ} \mathrm{C}$ for 5 minutes each under $\mathrm{Ar}$ ambient conditions using a Lindberg annealing furnace. This procedure of cumulative annealing was followed so as to duplicate the conditions under which the electrical measurements were investigated.

The samples were then analysed using XPS and TOF-SIMS. A PHI 5000 Versaprobe Scanning ESCA Microprobe was used to perform the XPS experiment. It has a monochromatic $\mathrm{Al} \mathrm{K}_{\alpha} \mathrm{X}$-ray beam $(1486.6 \mathrm{eV})$ with a $100 \mu \mathrm{m}$ diameter spot size. The raster area was $1 \times 1 \mathrm{~mm}$ and a sputter rate of $18 \mathrm{~nm} / \mathrm{min}$ was employed. The TOF SIMS experiment was performed using an ION-TOF TOF SIMS 5. This equipment uses a pulsed 
$\mathrm{Bi}^{+}$primary ion beam $(1 \mathrm{pA}, 30 \mathrm{kV})$. In order to maximise the sensitivity, negative secondary ions were analysed. The vacuum pressure for both systems was in the $10^{-9}$ mbar region.

\section{Results and discussion}

The evolution of the $I-V$ characteristics of the Schottky photodiode are shown in Fig 1 . These show the diodes just before and after the annealing step in which they showed significant degradation in their electrical characteristics. Degradation modes considered were increase of reverse leakage current, decrease of barrier height, increase in series resistance and deviation from ideal thermionic emission (increase in ideality factor). The measurements were performed to investigate the influence of the insertion of $\mathrm{Ir}$ between $\mathrm{Ni}$ and $\mathrm{Au}$ on the $\mathrm{I}-\mathrm{V}$ characteristics of the diode. It was found that the insertion of Ir enhanced the electrical characteristics of the diode at higher annealing temperatures. The $I-V$ characteristics of the $\mathrm{Ni} / \mathrm{Au}$ Schottky diodes were optimum after annealing at $400{ }^{\circ} \mathrm{C}$. After $500{ }^{\circ} \mathrm{C}$ annealing the reverse current at lower voltages increased and the forward characteristics displayed different transport mechanisms at low voltages. The Ni/Ir/Au Schottky diode showed optimum characteristics after $500{ }^{\circ} \mathrm{C}$ annealing but after $600{ }^{\circ} \mathrm{C}$ annealing the reverse current increased significantly by up to 3 orders of magnitude. This agreed with results obtained by Miura et al. [8]. The difference in the manner of degradation of the two photodiodes showed that there were two different modes involved in the degradation of the samples. It has been suspected by Miura et al. [8] that when Au diffuses into the semiconductor it deteriorated the currentvoltage characteristics of a $\mathrm{Ni} / \mathrm{Au}$ Schottky diode by increasing the leakage current.

Fig. 2 and 3 show the depth profiles of the Ni/Au and Ni/Ir/Au metal contacts measured by XPS. These figures compare the evolution of the metal contacts deposited on AlGaN measured as deposited, for the optimised annealing temperatures (400 and $500{ }^{\circ} \mathrm{C}$ annealing for $\mathrm{Ni} / \mathrm{Au}$ and $\mathrm{Ni} / \mathrm{Ir} / \mathrm{Au}$ respectively) and after degradation (500 and $600{ }^{\circ} \mathrm{C}$ annealing for 
$\mathrm{Ni} / \mathrm{Au}$ and $\mathrm{Ni} / \mathrm{Ir} / \mathrm{Au}$ respectively). The depth profiles were used to determine the diffusion of the metals. Due to the overlap of the XPS peaks of Ga and $\mathrm{N}$ with $\mathrm{Al}$, only $\mathrm{Al}$ was shown in the figures.

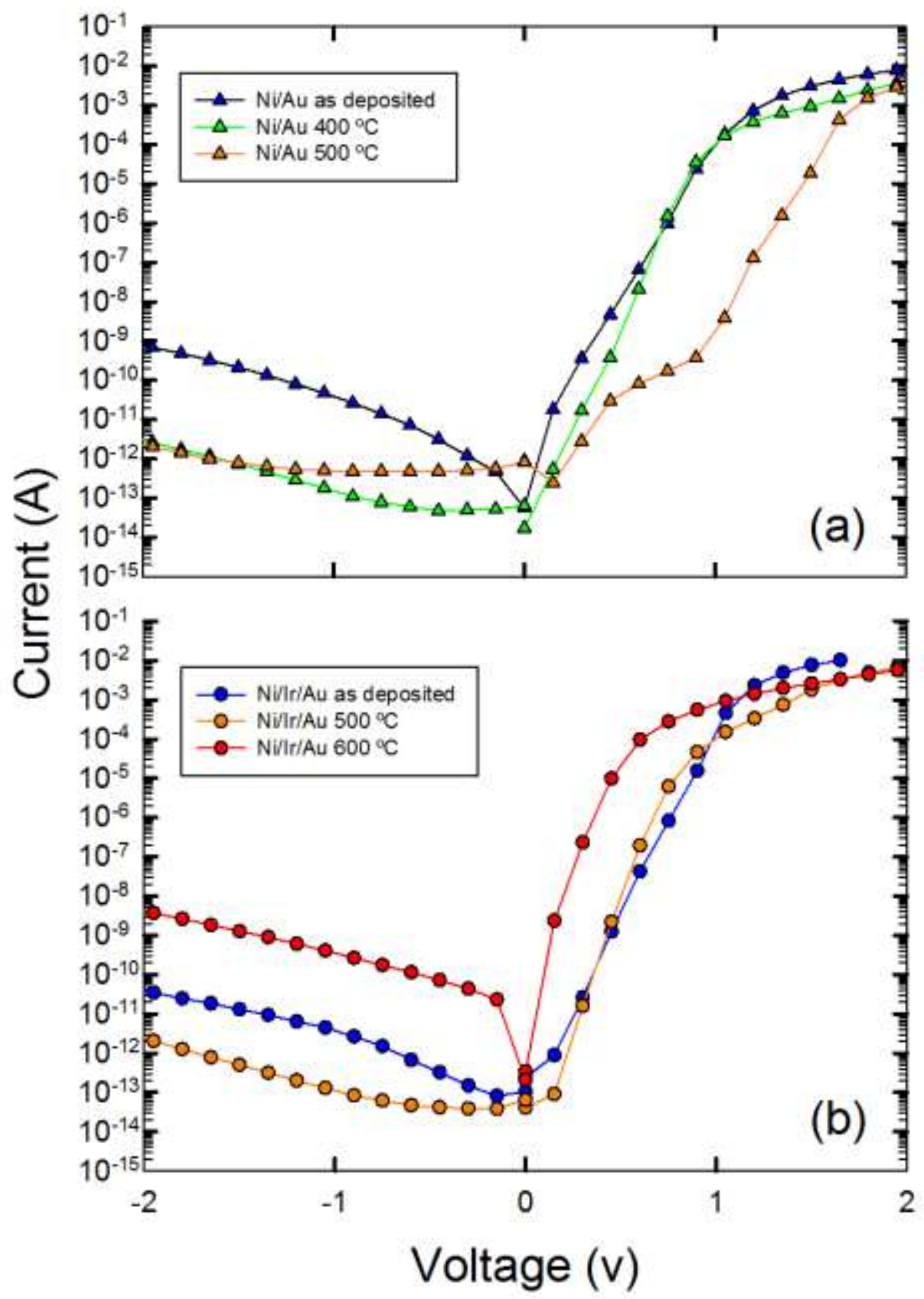

Fig. $1 \mathrm{I}-V$ characteristics of (a) $\mathrm{Ni} / \mathrm{Au}$ and (b) $\mathrm{Ni} / \mathrm{Ir} / \mathrm{Au}$ Schottky diodes measured after annealing. 


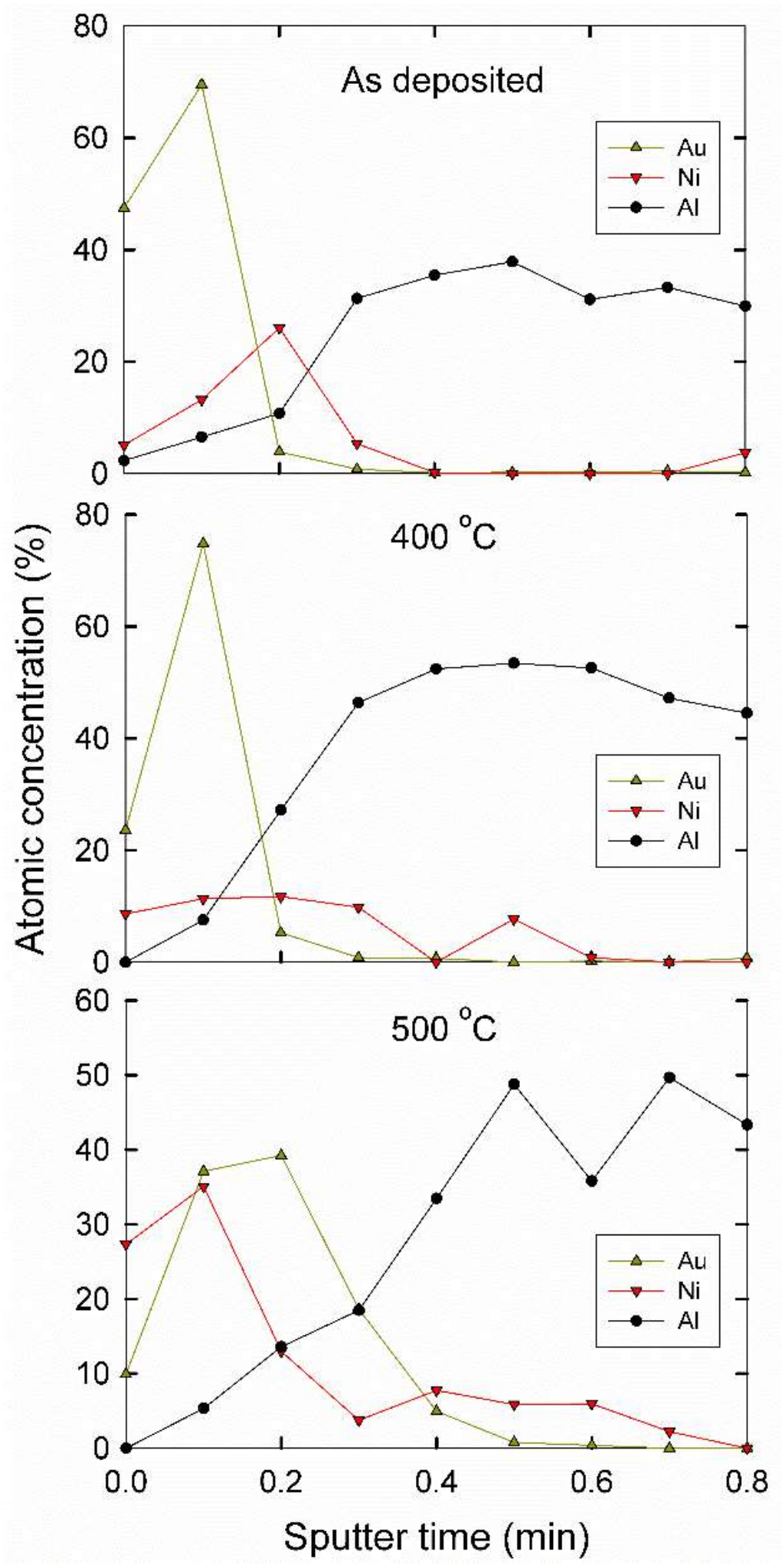

Fig. 2 XPS depth profiles of $\mathrm{Ni} / \mathrm{Au}$ deposited on $\mathrm{AlGaN}$ measured as deposited and after 400 and $500{ }^{\circ} \mathrm{C}$ annealing 

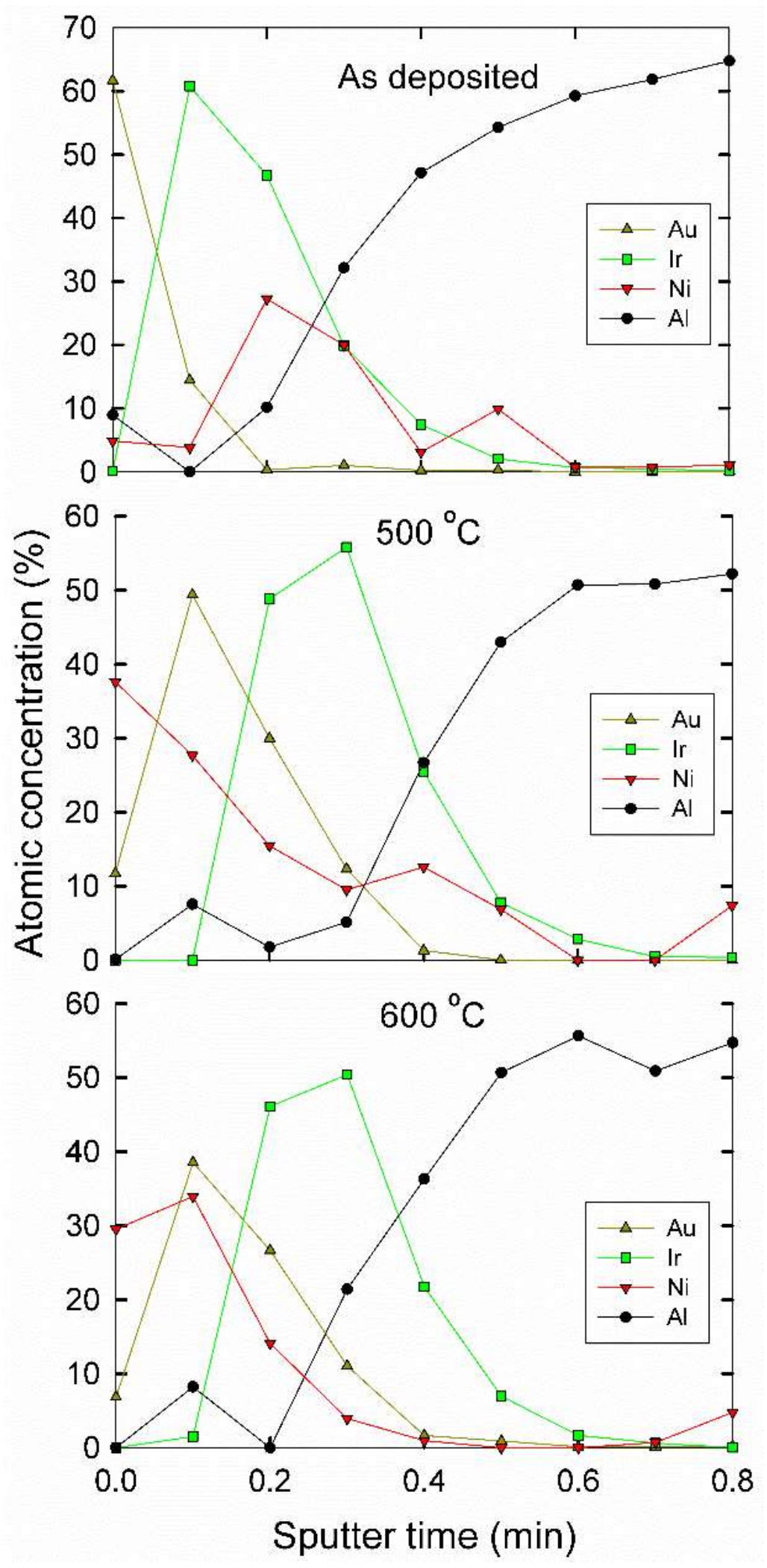

Fig. 3 XPS depth profiles of $\mathrm{Ni} / \mathrm{Ir} / \mathrm{Au}$ deposited on $\mathrm{AlGaN}$ measured as deposited and after 500 and $600{ }^{\circ} \mathrm{C}$ annealing 
The results of the as deposited $\mathrm{Ni} / \mathrm{Au}$ are as expected, with $\mathrm{Au}$ as the top layer followed by $\mathrm{Ni}$ then Al. The Au has a broader and higher peak compared to the Ni indicating that it was thicker than Ni. After $400{ }^{\circ} \mathrm{C}$ the Au diffused to the AlGaN substrate. After $500{ }^{\circ} \mathrm{C}$ annealing the Ni out-diffused to the top of the metal contact. In Fig. 3, Au was dominant closer to the surface as it was the top layer and decreased with depth. It was followed by Ir then Al. Even after high annealing temperatures, Ir formed a barrier between the $\mathrm{Au}$ and $\mathrm{AlGaN}$. The $\mathrm{Ni}$ seemed to have out-diffused after both $500{ }^{\circ} \mathrm{C}$ and $600{ }^{\circ} \mathrm{C}$ annealing temperatures.

Fig. 4 and 5 compare the Ni/Au and Ni/Ir Au metal layers on AlGaN using TOF-SIMS. Since Au was more sensitive to the negative ion analyses mode, its intensity was much larger than the other elements. The $\mathrm{Au}$ peaks in both the $\mathrm{Ni} / \mathrm{Au}$ and $\mathrm{Ni} / \mathrm{Ir} / \mathrm{Au}$ depth profiles at high temperatures up to approximately 2 minutes of sputtering were flat. It is suspected that the detector was saturated with $\mathrm{Au}$. In Fig. 4, the $\mathrm{Ni}$ was on the surface of the AlGaN semiconductor throughout all the annealing temperatures. It was only after $500{ }^{\circ} \mathrm{C}$ annealing that some of it out-diffused through the Au to the top of the metal scheme. Au diffused into the AlGaN substrate after $500{ }^{\circ} \mathrm{C}$ annealing. The depth profile in Fig. 5 of the Ni/Ir/Au metal scheme showed that $\mathrm{Ni}$ and Ir seem to have intermixed as deposited. Ir was on the surface of the $\mathrm{AlGaN}$ throughout the annealing temperatures. Ni out-diffused to the surface with each annealing temperature.

A comparison of the XPS and TOF-SIMS results show that both techniques have produced similar results. Au never diffused significantly through the Ir even after high annealing temperatures. This is in agreement with Okamoto et al. who found that Ir has a low solubility in $\mathrm{Au}$ [13]. In the Ni/Au Schottky diode the Au diffused through the Ni and the Au-AlGaN 

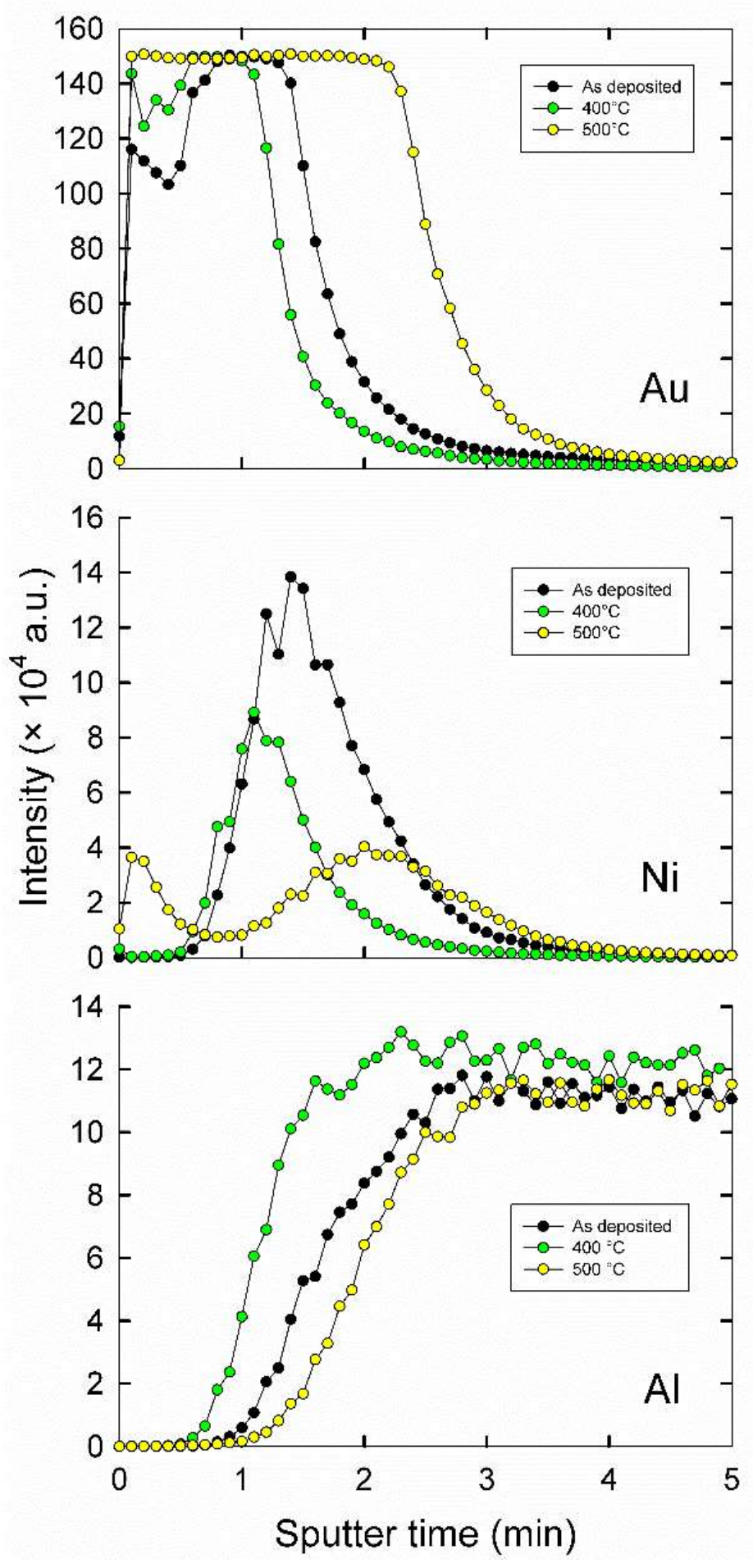

Fig. 4 TOF-SIMS depth profiles of Ni/Au metal layers deposited on $\mathrm{AlGaN}$ and measured after different annealing temperatures. 

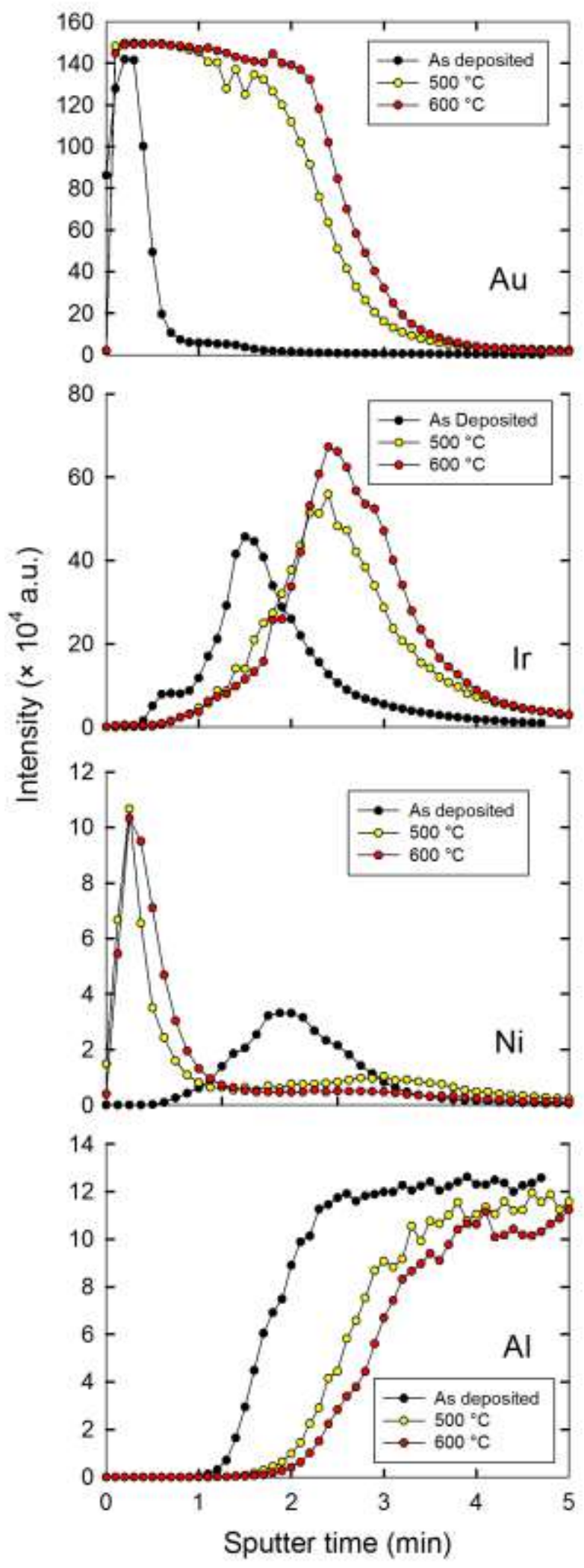

Fig. 5 TOF-SIMS depth profiles of $\mathrm{Ni} / \mathrm{Ir} / \mathrm{Au}$ metal layers deposited on $\mathrm{AlGaN}$ and measured after different annealing temperatures. 
contact seemed to have governed the transport mechanisms up to $400{ }^{\circ} \mathrm{C}$. After $500{ }^{\circ} \mathrm{C}$ the indiffusion of $\mathrm{Au}$ into the $\mathrm{AlGaN}$ substrate seems to have contributed to the degradation of the electrical characteristics of the $\mathrm{Ni} / \mathrm{Au}$ diode. The contact of $\mathrm{Ir}$ to $\mathrm{AlGaN}$ seems to have contributed to transport mechanisms of the $\mathrm{Ni} / \mathrm{Ir} / \mathrm{Au}$ diode since the depth profiles indicate that Ir was on the surface of the AlGaN substrate at different annealing temperatures. $\mathrm{Ni}$ is known to be soluble in $\mathrm{Au}$ [14] and mixable with Ir, explaining the rapid out-diffusion of $\mathrm{Ni}$ through both metals. According to the phase diagrams there are no relevant intermetallic compounds that could be formed.

\section{Conclusion}

The evolution of $\mathrm{Ni} / \mathrm{Au}$ and $\mathrm{Ni} / \mathrm{Ir} / \mathrm{Au}$ metal schemes were compared. The Ni/Au Schottky diodes deteriorated for annealing temperatures above $500{ }^{\circ} \mathrm{C}$, while the $\mathrm{Ni} / \mathrm{Ir} / \mathrm{Au}$ diodes degraded for temperatures above $600{ }^{\circ} \mathrm{C}$. The deterioration of the Ni/Au Schottky diode seemed to be due to the Au diffusing into the AlGaN substrate. The degradation of Ni/Ir/Au was due to a different transport mechanism as the reverse current increased by up to 3 orders of magnitudes. Thus Ir improves of the electrical properties of the $\mathrm{Ni} / \mathrm{Ir} / \mathrm{Au}$ diodes at high annealing temperature, acting as an effective diffusion barrier between the Au and the AlGaN substrate.

\section{Acknowledgements}

This work is based on the research supported by the National Research Foundation of South Africa (Grant specific unique reference number (UID) 87352) Opinions, findings and conclusions or recommendations are that of the authors, and that the NRF accepts no liability whatsoever in this regard. 


\section{References}

[1] S. Nakamura and G. Fasol, The Blue Laser Diode (Springer-Verlag, Berlin), 1997.

[2] S.P. Denbaars, Proceedings of the IEEE, 85 (11) 1997.

[3] M. Razeghi and A. Rogalski, J. Appl. Phys., 79 (10) (1996) 7433.

[4] P.N.M. Ngoepe, W.E. Meyer, M. Diale, F.D. Auret, and L. van Schalkwyk, Physica B 407 (2012) 1628.

[5] S.M. Sze, Physics of Semiconductor Devices, 2nd ed. (John Wiley and Sons, New York), 1981.

[6] J.K. Sheu, Y.K. Su, G.C. Chi, W.C. Chen, C.Y. Chen, C.N. Huang, J.M. Hong, Y.C. Yu, C.W Wang., and E.K. Lin, J. Appl. Phys. 83 (6) (1998) 3172.

[7] P.C. Chang, C.H. Chen, S.J. Chang, Y.K. Su, C.L. Yu, P.C. Chen, and C.H. Wang, Semicond. Sci. Tecnol., 19 (2004) 1354.

[8] N. Miura, T. Nanjo, M. Suita, T. Oishi, Y. Abe, T. Ozeki, H. Ishikawa, T. Egawa, and T. Jimbo, Solid-State Electron., 48 (2004) 689.

[9] A.C. Schmitz, A.T. Ping, M. Asif Khan, Q. Chen, J.W. Yang, and I. Adesida, J. Electron. Mater., 47 (4) (1998) 255.

[10] S. Arulkumaran, T. Egawa, G.Y. Zhao, H. Ishikawa, T. Jimbo, and M. Umeno, Jpn. J. Appl. Phys., 39 (2000) L351.

[11] P.N.M. Ngoepe, W.E. Meyer, M. Diale, F.D. Auret, and L. van Schalkwyk, Physica B 439 (2014) 119. 
[12] M. Diale, F.D. Auret, N.G. van der Berg, R.G. Odendaal, and W.D. Roos, Appl. Surf. Sci., 246 (2005) 279.

[13] H. Okamoto and T. B. Massalski, Bulletin of Alloy Phase Diagrams 5 (4) (1984) 381.

[14] H. Okamoto and T. B. Massalski, Phase Diagrams of Binary Gold Alloys. Materials Park, OH: ASM Int., 1987, p. 196. 